\title{
Mapping of Research Performance on Materials Science in India: A Study Based on Clarivate Analytics-Web of Science Database
}

\author{
Chandran Velmurugan* \\ Researcher,Department of Library and Information Science,Periyar University, India
}

Submission: September 24, 2018; Published: October 03, 2018

*Corresponding author: Chandran Velmurugan, Researcher,Periyar University, Salem, Tamilnadu, India, Email: murugan73@gmail.com

\begin{abstract}
This research has been made an attempt to identify the growth rate of research productivity and characteristics of scholarly publications published by Indian Scientists and researchers on Materials Science during 2006-2015. This study describes and focus the various factors such as manuscript and language based distribution; chronology wise distribution; growth rate of literature; country wise distribution; authorship pattern; Degree of Collaboration (DC); ranking of highly cited authors (top 10); ranking of highly cited institutions (top 15); highly cited journals on Material Science (top 15); research area wise distribution and source title wise distribution etc. the results revealed that the highest number of (23.7\%) papers were published in 2015 and ranked first and the average publications per year was 89.7 and the average citations per paper was 1282.8. The lowest number of output (6.4\%) papers was published in 2006.
\end{abstract}

Keywords: Publication analysis; Research Trends; Material Science;Scientometrics; Bibliometrics; India

\section{Introduction}

Material Science is one of the thrust areas in the field of Science and Technology. Materials science is associated with new and advanced materials. The evolution of materials science starts historically from the ages such as Stone Age, Bronze Age, Iron Age, and steel age. Based on the geographical resources we can say that materials science is one of the oldest forms of engineering and applied science(Figure 1).

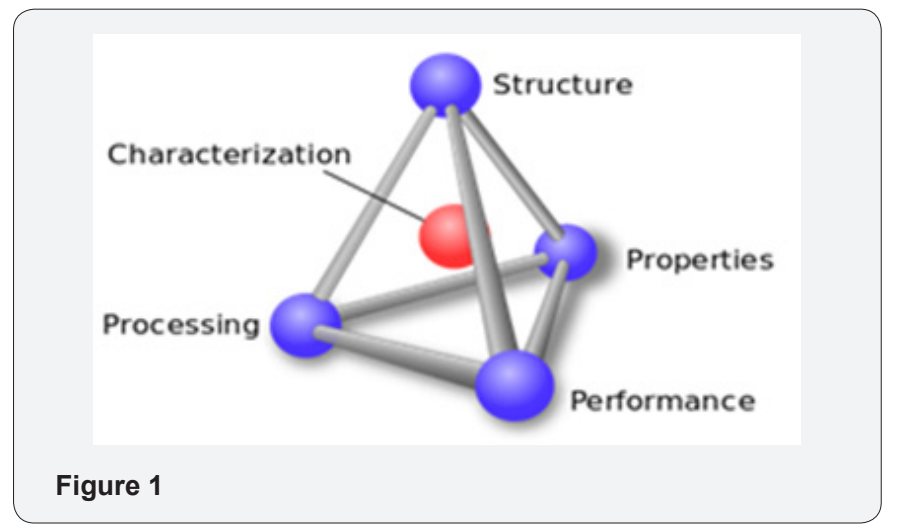

Materials science is a syncretic discipline hybridizing metallurgy, ceramics, solid-state physics, and chemistry. It is the first example of a new academic discipline emerging by fusion rather than fission [1]. Materials science is an important part of forensic engineering and failure analysis - investigating materials, products, structures or components which fail or do not function as intended, causing personal injury or damage to property. "The interdisciplinary field of materials science, also commonly termed materials science and engineering is the design and discovery of new materials, particularly solids"[2]. Encyclopedia Britannica defines Materials science is "the study of the properties of solid materials and how those properties are determined by a material's composition and structure as it grew out of an amalgam of solid-state physics, metallurgy, and chemistry." Materials Science is a field of study that looks at a material's atomic and molecular structure, its microscopic and macroscopic properties, how different processes affect its structure and properties, and how the material performs under different conditions (www.chegg.com/). According to merriam-webster dictionary, materials science is "the scientific study of the properties and applications of materials of construction or manufacture (such as ceramics, metals, polymers, and composites)" and "the study of the characteristics and uses of the various materials, such as metals, ceramics, and plastics, that are employed in science and technology" (www.thefreedictionary.com). Collins dictionary describes materials science is "a multidisciplinary science that studies manufacturing materials, esp. high-tech alloys, ceramics, and plastics" (www.collinsdictionary.com).

Materials science has acknowledged a good deal of attention from scientists and researchers. In most universities, many departments including physics, chemistry, chemical engineering, 
along with materials science departments, are involved in materials research. Research in materials science is vibrant and consists of many opportunities. The significant research areas such as Nanomaterials, biomaterials, Electronic, optical, and magnetic, Computational science and theory, Ceramics and glasses, industry, Composites, Polymers, Metal alloys, Semiconductors, and other fields such as metallurgy, solid state physics, chemistry, chemical engineering, mechanical engineering and electrical engineering. Numerous researches conducted by researchers all through the globe in the field of material science. Various Indian institutions covers academic, IITs, IIITs, and NITs, Universities and Research and Development (R\&D) institutions, institutes of national importance and industries are actively pursuing research in materials science discipline. For instance, the area of Materials science institutions and R\&Ds such as Indian Institute of Technology Madras (IITM), Chennai; Indira Gandhi Centre for Atomic Research (IGCAR), Kalpakkam; Indian Institute of Technology (IITK), Kharagpur; National Chemical Laboratory (NCL), Pune; Indian Institute of Technology Bombay (IITB), Mumbai and New Delhi; Central Leather Research Institute (CLRI), Chennai; Defence Metallurgical Research Laboratory (DMRL), Hyderabad; Indian Institute of Science (IISc), Bangalore; Indian Institute of Technology Bombay (IITB), Mumbai; Vikram Sarabhai Space Centre (VSSC), Trivandrum; Bhabha Atomic Research Centre (BARC), Mumbai; MIDHANI, Hyderabad; National Metallurgical Laboratory (NML), Jamshedpur; and IDPL Chemicals Limited, Hyderabad are the most effective and active institutions carrying out research in materials science in India.

Scientometrics is one of the purport metric tools by which the state of science and technology can be observed by means of overall scientific publications at a given level of specialization. It indicates that for situating a country in association with the world, an institution or organization in association with a country, and even an individual researcher or scientists in association with their own communities. In short, Scientometrics is nothing but science plus metrics. a number of studies have been carried out in various subjects by different scholars and researchers all over the global. Bibliometric / scientometirc tools can assist to decision-making and research management. It is not only can justify a decision or replace experts but also these indicators are practical tool which can be used in amalgamation of other indicators. Many scientometric researches have been investigated in the scholarly publications to focus on the research performance on the science in various discipline/domains [3-12]. Based on the observations, we found out that only few studies have been done on scientometrics in Materials Science by Indian scientists. Kochhar examined the scientific papers from Indian Institutions in seven types of materials such as metals and alloys, ceramics, aluminium, glass, composites, polymers and wood based on the database of INSDOC during 1980-89[13]. Walke and Dhawan analyzed the growth and publications size of the Indian publications in materials science in India for period from 1993 to
2001 based on Science Citation Index-Expanded Version (SCIE) of the Thomson-ISI[14]. The study focused the productivity and characteristics of materials science and other parameters such as research quality, priority and nature of collaborative trends, subject category and institutional distribution. Mohan studied the international collaborative papers of Indian scientists during 1995-99 as covered by Materials Science Citation Index for period between 1982 and 2008[15]. This study had made an attempt to highlight the research and development activity in the field of materials science in India. The results focused the collaborative countries and United States, Germany, France, UK and Japan were the top ranked countries. Fifty percent of the research papers were published by Indian Institutions and the major proportion of the collaboration were theoretical studies, metals \& alloys, electronic materials and super conducting materials. Recently Kademani; Anil Sagar and Bhanumurthy investigated the research and impact of materials science literature output by Indian researchers for the period of 1999-2008[16]. this study covered various dimensions such as activity index, domain wise contribution, citation impact, publication growth, highly productive authors, institutions, core journals and cited research output, collaboration with national as well as international level etc. the results showed that a total of 14849 scientific papers were produced by Indian scientists. The average number of citations per paper was 6.37 and the average number of paper per year was 1484.90. It was noticed that Indian Institute of Technology from Kharagpur got the first place with 1243 research output. Therefore, this study has been taken for the research as there is no such a study is carried out in this title and the range of output in the field of materials science by Indian researchers and scientists so far.

\section{Objectives, Materials and Methods}

The main purpose of this research is to identify the growth rate of research productivity on Material Science during the period. The other key objectives are manuscript and language based distribution, chronology wise distribution, growth rate of literature, country wise distribution, Authorship pattern, Degree of Collaboration (DC), Ranking of Highly cited authors (top 10), Ranking of Highly cited institutions (top 15), Highly cited journals on Material Science (top 15), Research Area wise distribution and Source Title wise distribution etc.

\section{Data Source for Research}

The sources for scientometrics as well as bibliometrics are always databases. a number of bibliometric databases are available in the market such as chemical abstracts for physics and chemistry, Compendex for engineering and technology, Embase for medical science, Inspec for physical science, Pascal for general database for several fields, Scopus and Web of Science databases are multidisciplinary databases. For the purpose of this research Web of Science database has been chosen. The Web of Science Core Collection database has been used to retrieve the data by the keyword i.e. 'Material Science' indexing from the bibliographic 
database of Web of Science covers Science Citation Index (SCI), Social Science Citation Index (SSCI), and Arts \& Humanities Citation Index (ACHI) during 2016. The study period (2006-2015) has been chosen for retrieving the source data. The study based on the scholarly publications of Material Science covering the period from 2006 to 2015 only using Web of Science Database. The study has some limitations such as: the study covers the national and international publications only; the study excludes the publications in regional language; it does not cover literature output from newspapers or magazines and the study does not cover the scholarly communications other than Material Science.

\section{Source Details}
a. Total number of Records
$: 897$
b. Number of Times Cited
$: 12828$
c. Number of Times Cited without self-citations: 12755
d. Citing Articles
$: 12513$
e. Citing Articles without self-citations: 12460
f. Average Citations per Item: 14.30
g. h-index
: 50 (Figure 2)

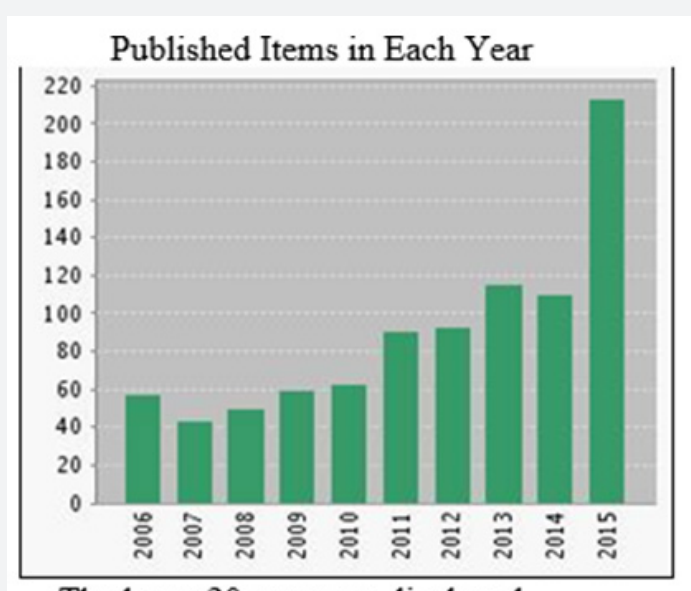

The latest 20 years are displayed

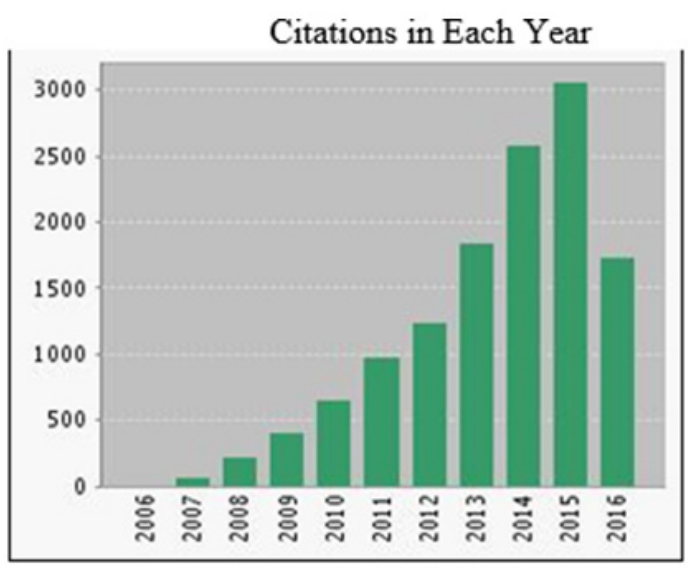

The latest 20 years are displayed

Figure 2

\section{Analysis and Results}

Manuscript and Language Based Distribution: It is seen from the Table 1 that the seven various types of research papers such as articles, reviews, proceedings paper, Editorial Materials, Review; Letters, and Book Review. It was found that the maximum number of $698(77.8 \%)$ literature output were comes under

Table 1: Type of documents. 18605994555 vcare@voltas.com research articles with 5359 total global citations and ranked first and followed by 146 review articles were published on Material Science and got placed second rank and the least number of only one paper $(0.1 \%)$ comes under book review and ranked least place. The results revealed that the predominant position and received by journal articles during the period of study[17](Figure 3).

\begin{tabular}{|c|c|c|c|c|c|}
\hline Sl. No & Document Type & Records & Percent & TLCS & TGCS \\
\hline 1 & Article & 698 & 77.8 & 53 & 5359 \\
\hline 2 & Review & 146 & 16.3 & 15 & 6923 \\
\hline 3 & $\begin{array}{c}\text { Article; Proceedings } \\
\text { Paper }\end{array}$ & 38 & 4.2 & 2 & 517 \\
\hline 4 & Editorial Material & 8 & 0.9 & 0 & 16 \\
\hline 5 & Review; Book Chapter & 4 & 0.4 & 0 & 10 \\
\hline 6 & Letter & 2 & 0.2 & 0 & 3 \\
\hline 7 & Book Review & 1 & 0.1 & 0 & 0 \\
\hline \multicolumn{2}{|c|}{ Total } & 897 & 100 & 70 & 12828 \\
\hline
\end{tabular}



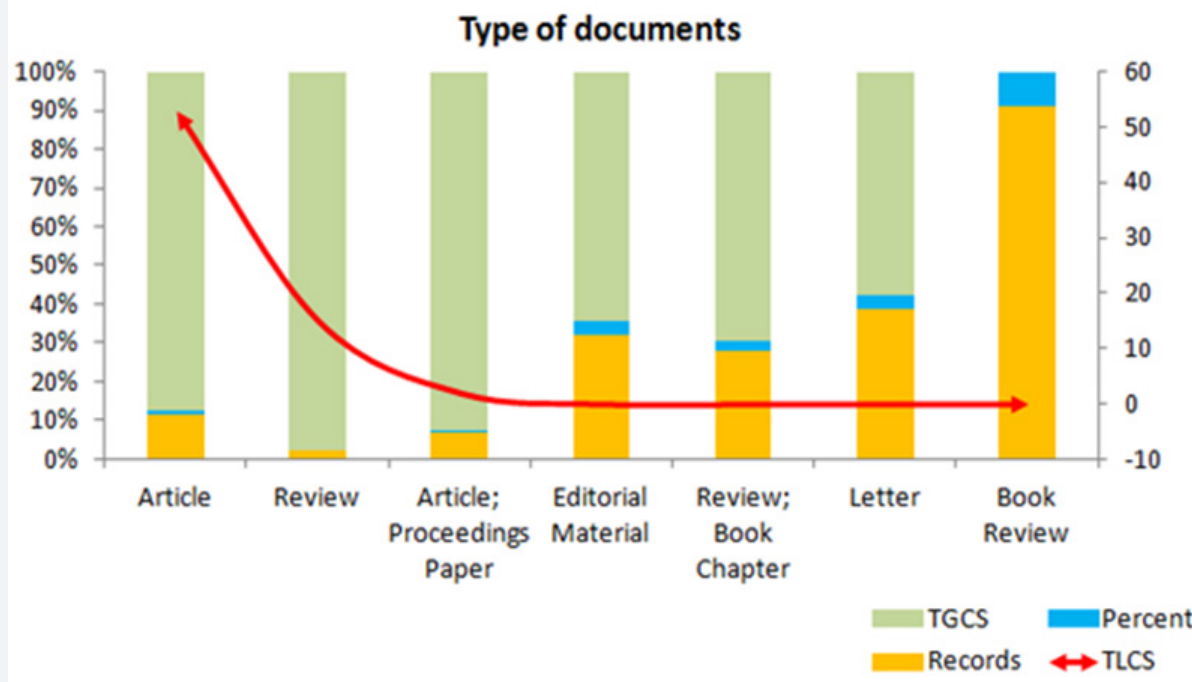

Figure 3: Type of documents.

Language Wise Distribution: It is identified by the researcher that the language wise distribution of contribution on Material Science literature in India. The scholarly communications were published only two languages such as English and Chinese. The results indicate that the major proportion of 896 (99.9\%) research articles with 12,814 total global citations were published through English language effectively and followed by Chinese $(0.1 \%)$ only one article with 14 global citations during the period of study[18].

Chronology Wise Distribution: It is inferred from the Table 2 that has been identified the year wise distribution of contributions on Material Science in India during the period from 2006 to 2015. It represents that out of 897 research papers, the highest number i.e. 213 (23.7\%) papers were published with 407 total global citations in 2015 and had ranked first and followed by $110(12.3 \%)$ articles which were published with 554 citations in 2014 and placed second rank. The average publications per

Table 2: Year-wise distribution.

\begin{tabular}{|c|c|c|c|c|c|}
\hline Sl. No & Year & Records & Percent & TLCS & TGCS \\
\hline 1 & 2006 & 57 & 6.4 & 3 & 1190 \\
\hline 2 & 2007 & 44 & 4.9 & 5 & 1505 \\
\hline 3 & 2008 & 50 & 5.6 & 0 & 1675 \\
\hline 4 & 2009 & 60 & 6.7 & 11 & 1978 \\
\hline 5 & 2010 & 63 & 7.0 & 10 & 954 \\
\hline 6 & 2011 & 91 & 10.1 & 13 & 1552 \\
\hline 7 & 2012 & 93 & 10.4 & 12 & 1011 \\
\hline 8 & 2013 & 116 & 12.9 & 13 & 2002 \\
\hline 9 & 2014 & 110 & 12.3 & 3 & 554 \\
\hline 10 & 2015 & 213 & 23.7 & 0 & 407 \\
\hline \multicolumn{2}{|c|}{ Total } & 897 & 100 & 70 & 12828 \\
\hline
\end{tabular}

year was 89.7 and the average citations per paper was 1282.8 . The lowest number, i.e. 57 (6.4\%) papers were published with 1190 citations in 2006. The findings of the study show that the growth rate has been increased gradually from 2006 onwards. It was also noted that based on the global citations, in 2013 was the first rank with 2002 citations and followed by 2009 was the second rank with 1978 global citations. The declined trend in the number of scientific publications in Materials Science research was observed in 2007 with only 44 research publications and the citations was 1505 . It was also observed that the more number of research papers in a particular year received more number of citations, which represents the quality and quantity of research invariably go hand in hand. It is evaluated the trend line analysis to determine the exponential logarithmic values for Material Science literature output in India. Accordingly, the trend line of exponential growth and the value is $y=35.8 \mathrm{e}^{0.1465 \mathrm{x}}$ and the $\mathrm{R}^{2}$ value is 0.8548 (Figure 4)[19]. 


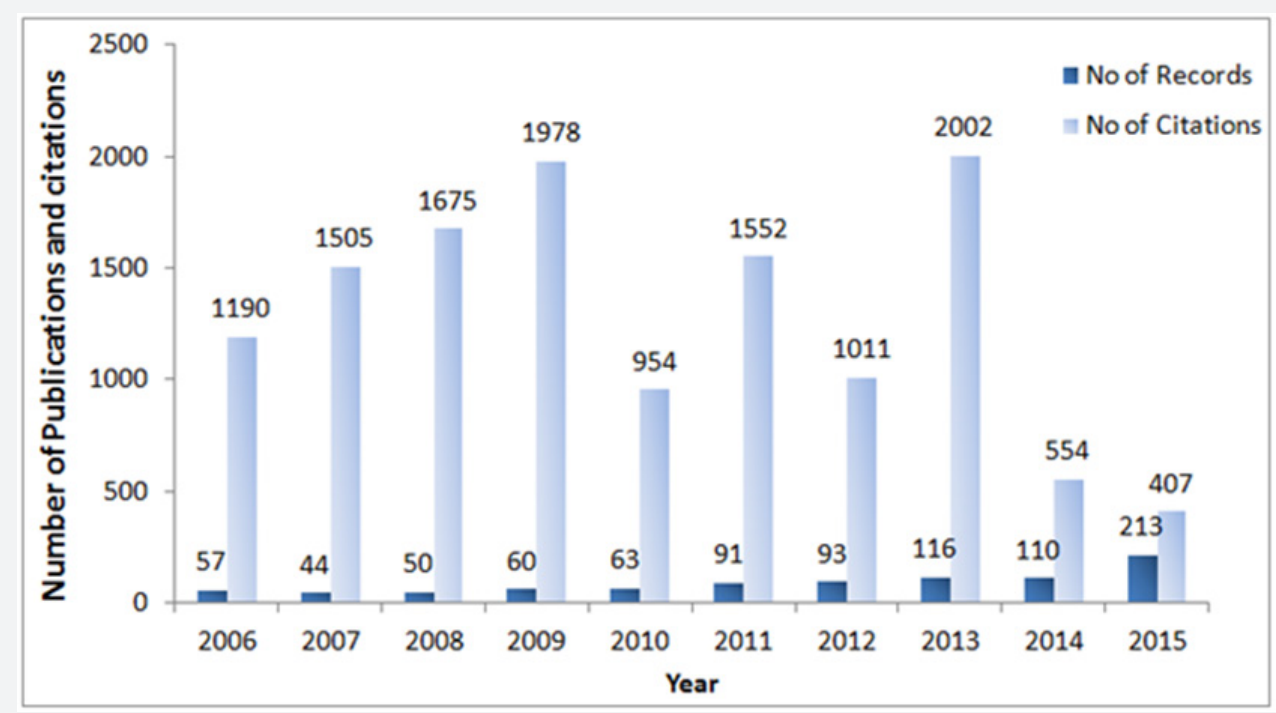

Figure 4: Yearwise distribution.

Growth Rate of Literature: Relative Growth Rate (RGR) is the increase the number of publications or research output per unit of time. There exists a direct relation between the relative growth rate and doubling time (DT). The relative growth rate and the doubling time of scholarly publications has been evaluated using the formula [20].

$$
R(a)=\frac{(W 2-W 1)}{(T 2-T 1)}
$$

$\mathrm{R}(\mathrm{a})=$ Relative Growth Rate over the specific period of interval

$\mathrm{W} 1=\log \mathrm{w} 1$ (Natural log of initial number of publications)

$\mathrm{W} 2=\log \mathrm{w} 2$ (Natural log of final number of publications)

$\mathrm{T} 2-\mathrm{T} 1=$ Unit difference between the initial and final time

$\mathrm{R}(\mathrm{a})=$ Per unit of publications per unit of time (yr)

\section{Doubling Time (DT)}

There exists a direct equivalence between the relative growth rate and the doubling time. If the number of articles or pages of a subject doubles during a given period, then the difference between the logarithms of numbers at the beginning and end of this period

Table 3: Growth Rate of literature on Material Science.

\begin{tabular}{|c|c|c|c|c|c|c|c|c|}
\hline Year & R.o/p & Cum.o/p & $\log _{e} \cdot 1 p$ & $\log _{e} 2 p$ & $\operatorname{Rt}(\mathbf{P})$ & Mean R(a)1-2 & $\operatorname{Dt}(\mathrm{P})$ & M Dt (a) 1-2 \\
\hline 2006 & 57 & 57 & 4.04 & - & - & \multirow{5}{*}{1.67} & - & \multirow{5}{*}{0.617} \\
\hline 2007 & 44 & 101 & 3.78 & 4.61 & 0.83 & & 0.83 & \\
\hline 2008 & 50 & 151 & 3.91 & 5.02 & 1.11 & & 0.62 & \\
\hline 2009 & 60 & 211 & 4.09 & 5.35 & 1.26 & & 0.55 & \\
\hline 2010 & 63 & 274 & 4.14 & 5.61 & 1.47 & & 0.47 & \\
\hline
\end{tabular}




\section{International Journal of Environmental Sciences \& Natural Resources}

\begin{tabular}{|c|c|c|c|c|c|c|c|c|}
\hline 2011 & 91 & 365 & 4.51 & 5.89 & 1.38 & \multirow{5}{*}{1.568} & 0.50 & \multirow{5}{*}{0.442} \\
\hline 2012 & 93 & 458 & 4.53 & 6.13 & 1.60 & & 0.43 & \\
\hline 2013 & 116 & 574 & 4.75 & 6.35 & 1.60 & & 0.43 & \\
\hline 2014 & 110 & 684 & 4.70 & 6.53 & 1.83 & & 0.37 & \\
\hline 2015 & 213 & 897 & 5.36 & 6.79 & 1.43 & & 0.48 & \\
\hline Total & 897 & & & & & 1.619 & & 0.529 \\
\hline
\end{tabular}

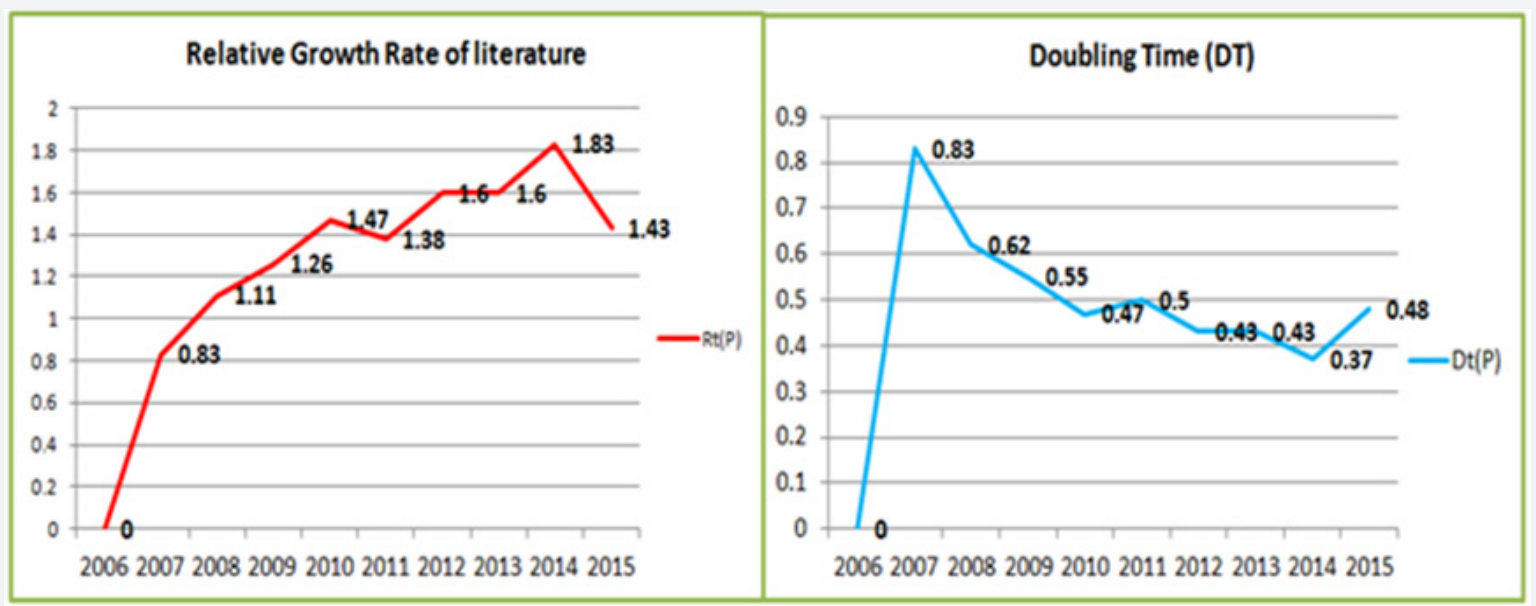

Figure 5: Growth Rate of literature on Material Science.

\section{Country Wise Distribution}

Table 4 shows that out of 64 countries, the maximum number of 884 (98.6\%) output with 12682 global citations have published from Indian scientists on Material Science during the period of study. The maximum number of collaborative countries such as United States (68), UK (29), Germany (20), Japan (18), China (18) and South Korea (17) were published more research articles and collaborated with India. The least number of collaborative countries such as Albania, Argentina, Bahrain, Bangladesh,
Chile, Croatia, Denmark, Ecuador, Egypt, Ethiopia, Greece, Iran, Lithuania, Madagascar, Mauritius, Mexico, New Zealand, Oman, Qatar, Slovenia, Thailand, Togo, Tunisia, Ukraine were each one research papers with below 0.2 percent. The findings of the study indicates that the majority of literature on Material Science were associated with USA, UK, Germany and Japan and it shows that the researchers and scientists from those countries were interesting to publish their research papers in India and eager to collaborative with Indian Scientists(Figures6 \& 7)[23].

Table 4: Country wise distribution.

\begin{tabular}{|c|c|c|c|c|c|}
\hline SI. No & Country & Records & Percent & TLCS & TGCS \\
\hline 1 & India & 884 & 98.6 & 70 & 12682 \\
\hline 2 & USA & 68 & 7.6 & 5 & 2016 \\
\hline 3 & UK & 29 & 3.2 & 0 & 1082 \\
\hline 4 & Germany & 20 & 2.2 & 2 & 934 \\
\hline 5 & Japan & 18 & 2 & 4 & 1408 \\
\hline 6 & Peoples R China & 18 & 2 & 1 & 883 \\
\hline 7 & South Korea & 17 & 1.9 & 3 & 190 \\
\hline 8 & Australia & 13 & 1.4 & 3 & 121 \\
\hline 9 & Canada & 11 & 1.2 & 2 & 117 \\
\hline 10 & France & 11 & 1.2 & 1 & 290 \\
\hline 11 & Unknown & 11 & 1.2 & 0 & 54 \\
\hline 12 & Saudi Arabia & 10 & 1.1 & 0 & 59 \\
\hline
\end{tabular}


International Journal of Environmental Sciences \& Natural Resources

\begin{tabular}{|l|c|c|c|c|c|}
\hline 13 & Finland & 8 & 0.9 & 8 & 0 \\
\hline 14 & Malaysia & 7 & 0.8 & 0 & 51 \\
\hline 15 & Italy & 6 & 0.7 & 1 & 157 \\
\hline 16 & Netherlands & 6 & 0.7 & 1 & 44 \\
\hline 17 & South Africa & 6 & 0.7 & 0 & 34 \\
\hline 18 & Taiwan & 6 & 0.7 & 6 & 95 \\
\hline 19 & Turkey & 6 & 0.7 & 0 & 56 \\
\hline
\end{tabular}
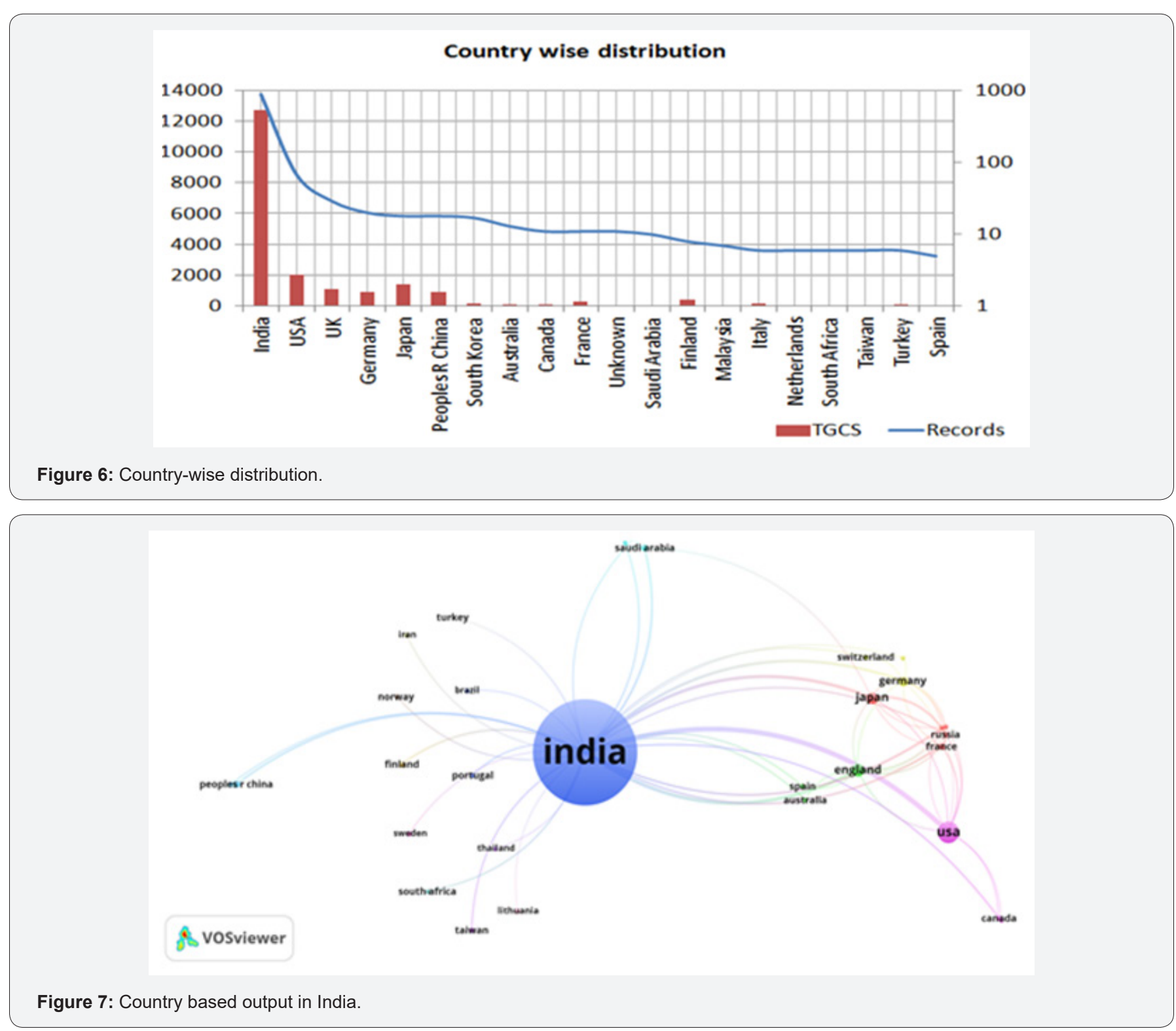

\section{Authorship Pattern}

Table 5 represents the authorship pattern of present study. Of the 3648 research papers, the majority of 208 (23.19\%) articles was contributed by three authors and ranked first and followed by two authors with 181 articles (20.18\%) and got placed second. Four authors have published 159 papers $(17.73 \%)$ and ranked third position, five authors with 103 (11.48\%) research papers and got occupied fourth place and single authors with 81 papers $(9.03 \%)$ and ranked sixth position. The least number of only $2(0.22 \%)$ papers have published by ten authors and ranked the eleventh position. The findings of the study reveal that the three authored papers were predominant and the collaborative research trend has seen on Material Science research during the period of study. 
Table 5: Authorship pattern.

\begin{tabular}{|c|c|c|c|c|c|c|}
\hline Sl. No & Pattern & No of Papers & $\%$ & Total output & Total \% & Rank \\
\hline 1 & Single author & 81 & 9.03 & 81 & 9.03 & VI \\
\hline 2 & Two authors & 181 & 20.18 & 362 & 29.21 & II \\
\hline 3 & Three authors & 208 & 23.19 & 624 & 52.4 & I \\
\hline 4 & Four authors & 159 & 17.73 & 636 & 70.13 & III \\
\hline 5 & Five authors & 103 & 11.48 & 515 & 81.61 & IV \\
\hline 6 & Six authors & 83 & 9.25 & 498 & 90.86 & $\mathrm{~V}$ \\
\hline 7 & Seven authors & 28 & 3.13 & 196 & 93.99 & VII \\
\hline 8 & Eight authors & 22 & 2.45 & 176 & 96.44 & VIII \\
\hline 9 & Nine authors & 12 & 1.34 & 108 & 97.78 & IX \\
\hline 10 & Ten authors & 2 & 0.22 & 20 & 98 & $\mathrm{XI}$ \\
\hline 11 & $\begin{array}{c}\text { More than ten } \\
\text { authors }\end{array}$ & 18 & 2 & 432 & 100 & $\mathrm{x}$ \\
\hline \multicolumn{2}{|c|}{ Total } & 897 & 100 & 3648 & & \\
\hline
\end{tabular}

\section{Degree of Collaboration (DC)}

Table 6 depicts that the growth of research and the degree of collaboration of Material Science in Indian Scientists during the period of study. Out of 897 publications, the major of $816(90.97 \%)$ articles were published by multi-authors whereas the remaining $81(9.03 \%)$ of articles were by solo authors. It was noted that the year wise degree of collaborative ranges from 0.8 to 0.96 and the average ratio value is 0.91 .

Table 6: Degree of Collaboration (DC) on Material Science.

\begin{tabular}{|c|c|c|c|c|c|c|}
\hline$\#$ & Year & Single author & Cum. Authors & Multi-authors & Cum. Authors & DC \\
\hline 1 & 2006 & 5 & - & 52 & - & 0.91 \\
\hline 2 & 2007 & 7 & 12 & 37 & 89 & 0.84 \\
\hline 3 & 2008 & 11 & 23 & 39 & 128 & 0.78 \\
\hline 4 & 2009 & 12 & 35 & 48 & 176 & 0.8 \\
\hline 5 & 2010 & 7 & 42 & 56 & 232 & 0.89 \\
\hline 6 & 2011 & 13 & 55 & 78 & 310 & 0.86 \\
\hline 7 & 2012 & 4 & 59 & 89 & 399 & 0.95 \\
\hline 8 & 2013 & 5 & 64 & 111 & 510 & 0.96 \\
\hline 9 & 2014 & 9 & 73 & 101 & 611 & 0.91 \\
\hline 10 & 2015 & 8 & 81 & 205 & 816 & 0.96 \\
\hline \multicolumn{2}{|c|}{ Total } & 81 & & 816 & 897 & 0.91 \\
\hline \multicolumn{2}{|c|}{ Percentage (\%) } & 9.03 & & 90.97 & 100 & \\
\hline
\end{tabular}

For the present study, to measure the degree of collaboration in quantitative terms, the formula of K. Subrahmanyam (1983) was used.

$\mathrm{C}=\mathrm{Nm} / \mathrm{Nm}+\mathrm{Ns}$

Where,

$\mathrm{C}=$ represents the degree of collaboration in a discipline

$\mathrm{Nm}=$ represents the number of multi-authored papers

Ns= represents the number of single-authored papers

Therefore, the value of $\mathrm{C}$ is $=\frac{816}{816+81}=\frac{816}{897}=0.91$

Likewise, the degree of collaboration is determined in every year and presented in below.
Based on the above analysis, the single authored research articles on Material Science show decreasing trend whereas the multi-authored publications on Material Science reveal the progressive trend and it indicates that Material Science is reaching towards collaborative research.

\section{Ranking of Highly Cited Authors (Top 10)}

It is shown in the Table 7 analyzing the ranking of highly cited authors on Material Science during the study period. Out of 3,648 authors, only highly cited top 10 individual authors were taken for the present study. Among the top 10 highly cited authors, the maximum number of research papers were produced by "Singh AK" with 1093 global citations and ranked first and followed by "Asokamani R" and “Geetha M" and "Gogia AK "who received 1029 
citations with only one article and they ranked second position respectively. It is very interesting to note that the remaining 21 authors such as Bellouin N, Berntsen T, Bond TC, DeAngelo BJ, Doherty SJ, Fahey DW, Flanner MG, Forster PM, Ghan S, Guttikunda
SK, Hopke PK, Jacobson MZ, Kaiser JW, Karcher B, Kinne S, Klimont Z, Koch D, Kondo Y, Lohmann U, Quinn PK, and Sarofim MC were third rank with 687 citations publishing only one research paper respectively.

Table 7: Ranking of Highly cited authors (top 10).

\begin{tabular}{|c|c|c|c|c|c|c|c|c|c|}
\hline$\#$ & Author & Records & Percent & TLCS & TLCS/t & TLCSx & TGCS & TGCS/t & Rank \\
\hline 1 & Singh AK & 12 & 1.3 & 2 & 0.48 & 1 & 1093 & 172.16 & I \\
\hline 2 & $\begin{array}{c}\text { Asokamani } \\
\text { R }\end{array}$ & 1 & 0.1 & 1 & 0.14 & 1 & 1029 & 147.00 & II \\
\hline 3 & Geetha M & 1 & 0.1 & 1 & 0.14 & 1 & 1029 & 147.00 & II \\
\hline 4 & Gogia AK & 1 & 0.1 & 1 & 0.14 & 1 & 1029 & 147.00 & II \\
\hline 5 & Bellouin N & 1 & 0.1 & 0 & 0.00 & 0 & 687 & 229.00 & III \\
\hline 6 & Berntsen T & 1 & 0.1 & 0 & 0.00 & 0 & 687 & 229.00 & III \\
\hline 7 & Bond TC & 1 & 0.1 & 0 & 0.00 & 0 & 687 & 229.00 & III \\
\hline 8 & DeAngelo BJ & 1 & 0.1 & 0 & 0.00 & 0 & 687 & 229.00 & III \\
\hline 9 & Doherty SJ & 1 & 0.1 & 0 & 0.00 & 0 & 687 & 229.00 & III \\
\hline 10 & Fahey DW & 1 & 0.1 & 0 & 0.00 & 0 & 687 & 229.00 & III \\
\hline
\end{tabular}

\section{Ranking of Highly Cited Institutions (Top 15)}

It is shown in Table 8 that institution wise contributions on Material Science and the total number of institution observed is 1089 . Here, only highly cited top 15 institutions was chosen for the present analysis. Institution wise total output of Indian Scientists on Material Science for 2006-2015 is based on science citation index. It is noted that 'Indian Institute Technology' ranked first and noted to be the most productive institution that has published a maximum number of articles (71) with total global citations was 1796 on Material Science. It is followed by Defense Material Research Lab (India) which has cited 1049 citations producing 4 articles and it is placed to the second rank. The third place is taken by Vellore Institute of Technology from India which has been cited 1045 citations with 3 outputs in this study period. The fourth place occupied by Kaveri Engine Program (India) which has cited 1029 citations with only one paper. The next place taken by Forschungszentrum Julich from Germany has produced 784 citations with only 2 articles. Among the top 15 highly cited institutions, the least number of citations were 687 taken by two institutions such as China Meteorology Administration from China and Clarkson University from United States with only one record respectively.

Table 8: Ranking of Highly cited institutions (top 15).

\begin{tabular}{|c|c|c|c|c|c|c|}
\hline Rank & Institution & Country & Records & Percent & TLCS & TGCS \\
\hline 1 & Indian Inst Technology & India & 71 & 7.9 & 26 & 1796 \\
\hline 2 & $\begin{array}{l}\text { Defense Material } \\
\text { Research Lab }\end{array}$ & India & 4 & 0.4 & 1 & 1049 \\
\hline 3 & Vellore Inst Technology & India & 3 & 0.3 & 1 & 1045 \\
\hline 4 & Kaveri Engine Program & India & 1 & 0.1 & 1 & 1029 \\
\hline 5 & Forschungszentrum Julich & Germany & 2 & 0.2 & 0 & 784 \\
\hline 6 & Indian Inst Science & India & 35 & 3.9 & 2 & 769 \\
\hline 7 & $\begin{array}{c}\text { Environmental Production } \\
\text { Agency }\end{array}$ & USA & 2 & 0.2 & 0 & 756 \\
\hline 8 & University of Leeds & UK & 2 & 0.2 & 0 & 746 \\
\hline 9 & Kings College London & UK & 4 & 0.4 & 0 & 706 \\
\hline 10 & University of Washington & USA & 4 & 0.4 & 1 & 695 \\
\hline 11 & University of Michigan & USA & 2 & 0.2 & 0 & 692 \\
\hline 12 & University of Colorado & USA & 2 & 0.2 & 0 & 689 \\
\hline 13 & University of Illinois & USA & 2 & 0.2 & 0 & 688 \\
\hline 14 & China Meteorol Adm & China & 1 & 0.1 & 0 & 687 \\
\hline 15 & Clarkson University & USA & 1 & 0.1 & 0 & 687 \\
\hline
\end{tabular}




\section{Highly cited journals on Material Science (Top 15)}

It is inferred that out of 487 journals on Material Science, only highly cited top 15 journals with more than 100 highly cited journals have been chosen for the present study. The study reveals that the maximum number of (1076) global citations with two research papers published in "Progress in Materials Science" and occupied the first rank, and followed by 716 total citations

Table 9: Highly cited journals (top 15).

\begin{tabular}{|c|c|c|c|c|}
\hline S. No & Journal & Total Records & Total Percent & Total Citations \\
\hline 1 & Progress in Materials Science & 2 & 0.2 & 1076 \\
\hline 2 & Chemical Society Reviews & 5 & 0.6 & 716 \\
\hline 3 & Journal of Geophysical Research-Atmospheres & 1 & 0.1 & 687 \\
\hline 4 & AngewandteChemie-International Edition & 9 & 1 & 409 \\
\hline 5 & International Materials Reviews & 3 & 0.3 & 349 \\
\hline 6 & $\begin{array}{l}\text { Progress in Crystal Growth and Characterization of } \\
\text { Materials }\end{array}$ & 2 & 0.2 & 347 \\
\hline 7 & Journal of Hazardous Materials & 3 & 0.3 & 329 \\
\hline 8 & Heat Transfer Engineering & 1 & 0.1 & 319 \\
\hline 9 & Trends in Food Science \& Technology & 1 & 0.1 & 310 \\
\hline 10 & Nanomedicine-Nanotechnology Biology and Medicine & 1 & 0.1 & 248 \\
\hline 11 & Acta Materialia & 4 & 0.4 & 221 \\
\hline 12 & Chemical Reviews & 1 & 0.1 & 172 \\
\hline 13 & Journal of Materials Science & 16 & 1.8 & 161 \\
\hline 14 & Journal of Physics D-Applied Physics & 2 & 0.2 & 160 \\
\hline 15 & Journal of Biomedical Nanotechnology & 4 & 0.4 & 156 \\
\hline
\end{tabular}

\section{Research Area Wise Distribution}

It is identified 69 Research Areas on Material Science during the period between 2001 and 2015. Out of 69 research fields, only top 25 research disciplines were counted for the present study. Table 10 represents that the maximum number of 217 (24.19\%) research articles were produced from Materials Science and ranked first and followed by Chemistry with 211 (23.52\%) research papers were found and got placed second. The third rank has occupied by the discipline of Physics with 115 (12.82\%) papers. The research areas such as Polymer Science, Neurosciences with 5 research papers published in "Chemical Society Reviews" and it has been ranked second position. "Journal of Geophysical Research-Atmosphere" with 1 article and the total citations are 687 which received the third rank. Among the top 25 highly cited journals on Material Science, the least number of citations was $101(0.3 \%)$ research articles received from two journals such as "Reviews of Modern Physics" and "Soft Matter" respectively (Table 9).
Table 10: Research Area wise distribution.

\begin{tabular}{|c|c|c|c|}
\hline S. No & Research Areas & Records & \% \\
\hline 1 & Materials Science & 217 & 24.19 \\
\hline 2 & Chemistry & 211 & 23.52 \\
\hline 3 & Physics & 115 & 12.82 \\
\hline 4 & Science Technology other topics & 110 & 12.26 \\
\hline 5 & Engineering & 88 & 9.81 \\
\hline 6 & General Internal Medicine & 58 & 6.46 \\
\hline 7 & Pharmacology Pharmacy & 36 & 4.01 \\
\hline 8 & Metallurgy Metallurgical Engineering & 36 & 4.01 \\
\hline 9 & Polymer Science & 26 & 2.89 \\
\hline
\end{tabular}

Neurology, Dentistry Oral Surgery Medicine, Oncology Nuclear Science Technology, Instruments Instrumentation, Plant Sciences, Biotechnology and Applied Microbiology were published below 2 percent. Integrative Complementary Medicine, Computer Science, Public Environmental Occupational Health, Environmental Sciences Ecology, Surgery, Research Experimental Medicine Education Educational Research, Spectroscopy and Food Science Technology were identified found below one percent. The results show that the majority of papers were published in the disciplines of Materials Science and Chemistry during the period of study. 


\section{Source Title Wise Distribution}

Table 11 shows that out of 464 source journals, only top 15 leading journals were chosen for the present study. "Journal of Evolution of Medical and Dental Sciences" (46, 5.13\%) was the most productive source title and got occupied first rank among the top 25 during the period of study. The next productive source journal was "Journal of Materials Science" with 16 (1.78\%) research output and ranked second. The most productive third source journal was "Current Science" with 14 (1.56\%) research papers. The source journals such as Computational Materials Science, Pramana Journal of Physics, Journal of Oral and Maxillofacial Surgery, Journal of Infection and Public Health, Journal of Cancer Research and Therapeutics and IETE Technical Review were published below 6 (each five) papers and ranked 10th during the study period.

Table 11: Source Title wise distribution.

\begin{tabular}{|c|c|c|c|c|}
\hline S. No & Source Titles & Records & $\%$ & Rank \\
\hline 1 & Journal of Evolution of Medical and Dental Sciences & 46 & 5.13 & 1 \\
\hline 2 & Journal of Materials Science & 16 & 1.78 & 2 \\
\hline 3 & Current Science & 14 & 1.56 & 3 \\
\hline 4 & Journal of Ethnopharmacology & 12 & 1.34 & 4 \\
\hline 5 & RSC Advances & 10 & 1.15 & 5 \\
\hline 6 & $\begin{array}{c}\text { Nuclear Instruments Methods in Physics Research Section B Beam Interactions with Materials } \\
\text { and Atoms }\end{array}$ & 9 & 1.003 & 6 \\
\hline 7 & Annals of Indian Academy of Neurology & 9 & 1.003 & 6 \\
\hline 8 & AngewandteChemie International Edition & 9 & 1.003 & 6 \\
\hline 9 & Neurology (India) & 8 & 0.89 & 7 \\
\hline 10 & Materials and Manufacturing Processes & 8 & 0.89 & 7 \\
\hline 11 & Particuology & 7 & 0.78 & 8 \\
\hline 12 & Journal of Nanoscience and Nanotechnology & 7 & 0.78 & 8 \\
\hline 13 & Journal of Materials Science Technology & 7 & 0.78 & 8 \\
\hline 14 & Journal of Materials Education & 7 & 0.78 & 8 \\
\hline 15 & Indian Journal of Cancer & 7 & 0.78 & 8 \\
\hline
\end{tabular}

\section{Conclusion}

Materials Science is one of the driving forces in the field of Science and Technology. This present research tried to focus the publications productivity and characteristics such as author's productivity, country's collaboration, web of science research categories, contribution by subjects, institutions, of Indian authors published through the web of science bibliographic database for a period from 2006 to 2015. Based on the research output of Indian literature published by the Indian Scientists, the major findings are revealed. It is found that out of 897 research papers, the highest number $23.7 \%$ of papers were published with 407 total global citations in 2015 and ranked first and followed by $12.3 \%$ of articles which were published with 554 citations in 2014 and placed second rank. The lowest numbers $(6.4 \%)$ of papers were published in 2006. It is noted that the maximum number $98.6 \%$ of literature output with 12682 global citations have published by Indian scientists on Material Science during the period of study. The maximum number of collaborative countries such as United States (68), UK (29), Germany (20), Japan (18), China (18) and South Korea (17) were published more research articles and collaborated with India. It is noticed out of 897 publications, the major of 816 (90.97\%) articles were published by multi-authors whereas the remaining $81(9.03 \%)$ of articles were by solo authors. It was noted that the year wise degree of collaborative ranges from 0.8 to 0.96 and the average ratio value is 0.91 . Among the top 25 highly cited authors, the maximum number of research papers were produced by "Singh AK" with 1093 global citations and ranked first. It is investigated that out of 487 journals on Material Science, the maximum number of (1076) global citations with two research papers published in "Progress in Materials Science" and occupied the first rank, and followed by 716 total citations with 5 research papers published in "Chemical Society Reviews" and ranked second place.

It is analyzed the maximum number of 217 (24.19\%) research articles were produced from Materials Science and ranked first and followed by Chemistry with 211 (23.52\%) research papers were found and got placed second. The third rank has occupied by the discipline of Physics with 115 (12.82\%) papers. "Journal of Evolution of Medical and Dental Sciences" (46, 5.13\%) was the most productive source title and got occupied first rank among the top 25 during the period of study. The next productive source journal was "Journal of Materials Science" with $1.78 \%$ of research output and ranked second. The most productive third source journal was "Current Science" with $1.56 \%$ of research papers. Out of 456 funding agencies, the maximum number of $2.23 \%$ was provide by Council of Scientific and Industrial Research, New 
Delhi and followed by Department of Science and Technology $(1.67 \%)$ were provided. It is identified that the major proportion of research articles had been funded by Council of Scientific and Industrial Research as well as Department of Science and Technology and ranked first and second respectively.

\section{References}

1. Beaver D, Rosen R (1979) Scientific co-authorship, research productivity and visibility in the French scientific elite.Scientometrics 1(2): 133-149.

2. Kademani BS, Anil Sagar,Bhanumurthy K (2011) Research and impact of materials science publications in India: 1999-2008. Malaysian Journal of Library \& Information Science 16(2): 63-82.

3. Karki MMS, Garg KC, SharmaP (2000) Activity and growth of organic chemistry research in India during 1971-1989. Scientometrics 49(2): 279-288.

4. Kochhar VB, Subba Rao A, Arora AM,Elhence D(1996) Materials research in IndiaA quantitative analysis. InBibliometrics, scientometrics and Informetrics, edited by BM Gupta. Segment New Delhi, Indiapp. 154-163.

5. Materials science.

6. Materials science.

7. Materials science.

8. Materials science.

9. Materials science.

10. Materials science.

11. Mohan S, Gupta BM, Dhawan SM (2003) Materials science research and development in India: a scientometric analysis of international collaborative output. DESIDOC Bulletin of Information Technology 23(2): 11-23.

12. Price, Derek J de Solla (1981) The analysis of scientometric matrices for policy implications. Scientometrics 3(1): 47-53.
13. Rustum Roy (1979) interdisciplinary science on campus.In Interdisciplinary and Higher Education, JJ Kockelmans editor Pennsylvania State University Press, USA pp. 161-196.

14. Subramanyam K (1983) Bibliometric studies of research collaboration: A review. Journal of information Science 6(1): 33-38.

15. Velmurugan C, Radhakrishnan N (2015) Visualizing Energy and Environment Research Productivity in Australia: A Scientometric Profile.Asia Pacific Journal of Energy and Environment2(3): 145-160.

16. Velmurugan C, Radhakrishnan N (2017) Phytochemistry Research in India: A Scientometric Profile. International Journal of Information Science and Management 15(2):15-31.

17. Velmurugan C (2014a) Research Trends in Journal of Intellectual Property Rights (JIPR): A Bibliometric Study.Library Philosophy and Practice p. 1-16.

18. Velmurugan $\mathrm{C}(2014 \mathrm{~b})$ Research Trends in Indian Journal of Pure and Applied Physics (IJPAP) for the Year 2009 - 2012.Asian Review of Social Sciences 3(1): 24-28.

19. Velmurugan C (2018a) Twenty six year Analysis of Fossil Fuel Related Highly Cited Works: A Web of Science Based Scientometric Profile. Int J Environ Sci Nat Res 10(5): 555796

20. Velmurugan C (2018b) Nephrology Research Performance of Indian Scientists in Science Citation Index Expanded: A Scientometric Profile. JOJ uro\& nephron 5(2): 1-6.

21. Velmurugan C (2018c) Scholarly Communications of Nephrology by Indian Scientists in Science Citation Index Expanded: A Scientometric Profile. Library Philosophy and Practice 1716: 1-13.

22. Velmurugan C (2018d) An Application of the Bibliometric Law of Fossil Fuel Literature in Science Citation Index Expanded. Organic and Medicinal Chemistry International Journal4(5): 1-4.

23. Walke R, Dhawan SM (2007) Materials science research in India: A scientometric analysis. DESIDOC Bulletin of Information Technology 27(1): 69-76.

Your next submission with Juniper Publishers will reach you the below assets

- Quality Editorial service

- Swift Peer Review

- Reprints availability

- E-prints Service

- Manuscript Podcast for convenient understanding

- Global attainment for your research

- Manuscript accessibility in different formats

( Pdf, E-pub, Full Text, Audio)

- Unceasing customer service

Track the below URL for one-step submission https://juniperpublishers.com/online-submission.php 